\title{
Review
}

\section{Why Women Have More Alzheimer's Disease Than Men: Gender and Mitochondrial Toxicity of Amyloid- $\beta$ Peptide}

\author{
Jose Viña* and Ana Lloret \\ Department of Physiology, Faculty of Medicine, University of Valencia, Valencia, Spain
}

Accepted 24 March 2010

\begin{abstract}
The main risk factors for developing Alzheimer's disease (AD) are age and gender. The incidence of the disease is higher in women than in men, and this cannot simply be attributed to the higher longevity of women versus men. Thus, there must be a specific pathogenic mechanism to explain the higher incidence of AD cases in women. In this regard, it is notable that mitochondria from young females are protected against amyloid- $\beta$ toxicity, generate less reactive oxygen species, and release less apoptogenic signals than those from males. However, all this advantage is lost in mitochondria from old females. Since estrogenic compounds protect against mitochondrial toxicity of amyloid- $\beta$, estrogenic action may be important in protecting cells from amyloid- $\beta$ toxicity and suggests a possible treatment or prevention strategy for AD. Unfortunately, to date, clinical trials with Ginkgo biloba and other estrogenic therapies have not proved successful in treating AD. As such, more experiments and clinical trials are indeed warranted to find conditions in which estrogenic compounds may be useful to prevent or treat AD.
\end{abstract}

Keywords: Alzheimer's disease, amyloid- $\beta$ peptide, gender, mitochondria

\section{GENDER DIFFERENCES IN THE INCIDENCE OF ALZHEIMER'S DISEASE}

The increase in life expectancy in Western countries, particularly the US and Europe, has been associated with a parallel increase in age-related diseases. Dementia is the first cause of mental disorder greatly contributing to physical decline as defined by frailty and dependency of the older population [1]. Alzheimer's disease (AD) is manifested by a progressive loss of memory and cognition. It is the main cause of dementia and, in fact, about $60 \%$ of all cases of dementia are AD patients. According to the Alzheimer's Association [2], $\mathrm{AD}$ is a leading cause of death in the US.

*Corresponding author: Jose Viña, Department of Physiology, Faculty of Medicine, University of Valencia, Avda. Blasco Ibañez, 15, 46010 Valencia, Spain. Tel.: +34 963864 650; Fax: +34 963 864 642; E-mail: jvina@uv.es.
The main risk factor for AD is age, but gender is also very important. Table 1 shows that the proportion of persons suffering $\mathrm{AD}$ is always higher in women than in men. This is true of all groups studied, beginning at age 60-64 through the population over age 95. The increased incidence in later stages of life, i.e., when persons are over 80 , may be due to the higher longevity of females versus males. However, the increased incidence in persons at ages 60-80 cannot be attributed to the higher longevity of women versus men because at those ages, the death rate is too small to be a significant factor in the pathogenesis of the disease. Thus, there must be a specific pathogenetic mechanism to explain the higher incidence of AD cases in women compared to men. A possible explanation for the increased incidence of dementia in women is that they suffer higher rates of obesity, diabetes, and other conditions which increase the likelihood of developing AD. 
Table 1

Incidence of Alzheimer's disease in different age groups and genders. Figures are $\%$ of the population in the European community suffering Alzheimer's disease in each age-group

\begin{tabular}{crc}
\hline Age groups & Men & Women \\
\hline $60-64$ & 0.2 & 0.9 \\
$65-69$ & 1.8 & 1.4 \\
$70-74$ & 3.2 & 3.8 \\
$75-79$ & 7.0 & 7.6 \\
$80-84$ & 14.5 & 16.4 \\
$85-89$ & 20.9 & 28.5 \\
$90-94$ & 29.2 & 44.4 \\
$>95$ & 32.4 & 48.8 \\
\hline
\end{tabular}

Based on estimates of the Aging, Demographics, and Memory Study (ADAMS), $16 \%$ of women and $11 \%$ of men over the age of 71 years have dementia [2]. We have attempted to find an explanation for this based on the mitochondrial toxicity of $\mathrm{AD}$, and this is described below.

\section{MITOCHONDRIA GENERATE MORE REACTIVE OXYGEN SPECIES IN THE PRESENCE OF AMYLOID- $\beta$ PEPTIDE}

The fact that there is oxidative stress in AD has been very well documented thanks to the pioneering work of George Perry and Mark A. Smith [3]. Work from Catarina Oliveira and colleagues [4] indicates that there must be a mitochondrial involvement in the generation of oxidative stress associated with AD. In fact, as early as 1988 , these authors reported that mitochondrial function was impaired by the amyloid- $\beta$ peptide $(\mathrm{A} \beta)$ in PC12 cells [4]. The involvement of mitochondria in the pathogenic mechanism of $\mathrm{A} \beta$ toxicity was clearly established when it was reported that cells lacking mitochondria ( $\rho$ cells) were protected against the toxicity of $\mathrm{A} \beta$ [5]. Moreover, it was also described that a specific protein (ABAD, an isoform of alcohol dehydrogenase) was of capital importance to understand the binding and subsequent toxicity of $\mathrm{A} \beta$ in its interaction with mitochondria [6]

An important fact in this field is that $\mathrm{A} \beta$ blocks respiration $[7,8]$. This has, of course, important bioenergetic consequences (a lowering of the ATP/ADP ratio), but it is also important to explain the increase in reactive oxygen species (ROS) associated with mitochondria. In general terms, when the flow of electrons through the respiratory chain is blocked at any of the respiratory complexes, the production of ROS by mitochondria is very significantly increased. Pioneering work by the group of Britton Chance together with Alberto Boveris showed that $2 \%$ of the oxygen consumption in resting mitochondria is converted to superoxide rather than to water $[9,10]$. However, when the rate of respiration increases (i.e., when mitochondria change from state III to state IV), this proportion dramatically decreases. Therefore, the lowering rate of respiration, due to the presence of $\mathrm{A} \beta$ peptide, led the group of Catarina Oliveira and our own group to the idea that $\mathrm{A} \beta$ could increase the production of ROS.

We observed that incubation with $\mathrm{A} \beta$ peptide significantly increases the rate of oxidant release by mitochondria thus confirming previous results of Oliveira's group [7,11].

We attempted to find an explanation for this phenomenon. Work by Hani Atamna had shown that $\mathrm{A} \beta$ could bind to heme molecules present in the respiratory chain and interact with them and therefore interfere with their normal function in the transfer of electrons along the respiratory chain [12]. We took over from this idea and observed that incubation of mitochondria in the presence of $\mathrm{A} \beta$ resulted in an increase of oxidant production by mitochondria but that this was completely prevented by pre-incubation of $\mathrm{A} \beta$ with heme. Thus, heme protected the mitochondria from the attack by $\mathrm{A} \beta$ peptide because free heme was competing with that present in the respiratory chain complexes and protecting mitochondria against the toxicity of $\mathrm{A} \beta$ [11]. The involvement of mitochondria in aging as proposed originally by Jaime Miquel [13], and the fact that there is a gender difference between ROS production and mitochondria from females as compared with that of males, led us to study if mitochondria were involved in the gender differences in AD incidence. An important clue came from the fact that mitochondria from females produce fewer radicals than those from males.

\section{MITOCHONDRIA FROM FEMALES PRODUCE FEWER REACTIVE OXYGEN SPECIES THAN THOSE FROM MALES}

The question of why women live longer than men has been a focus of attention in our laboratory. We ruled out the possibility that this was due to sociological causes, because in many animal species like the Wistar rat or the white Swiss albino mouse, females also live longer than males. This is, however, not the case for all species and, for instance, the very commonly used 
mouse C57BL6 shows a different pattern of behavior: males live longer than females.

In any case, in both the human species and the Wistar rat, females live longer than males. We observed that both hepatic and brain mitochondria from female Wistar rats produce significantly less peroxides than those from males. However, ovariectomy completely reversed this trend and mitochondria from ovariectomized females produce the same amount of peroxides as those from males. Estrogen replacement therapy of ovariectomized females led to a low production of peroxides from mitochondria and in this case, ovariectomized females treated with estrogens produced fewer peroxides than males. Thus, we figured out that estrogens could be the reason for the low production of peroxides because of the antioxidant properties conferred to them by the phenolic structure of the A ring. However, the dose of estrogens normally used in estrogen replacement therapy in humans is approximately 8,000 times less than the recommended amount of vitamin $\mathrm{E}$ for human supplementation. Women under estrogen replacement therapy normally receive $50 \mu \mathrm{g}$ of estradiol whereas normally, vitamin $\mathrm{E}$ is usually administered at a dose of $400 \mathrm{mg} /$ day. Thus, the powerful antioxidant effect of estrogens could not be based on their chemical structure, but rather on their hormonal action [14]. This led us to conclude that estrogens might upregulate the expression of antioxidant genes.

\section{ESTROGENS (AND PHYTOESTROGENS) UPREGULATE THE EXPRESSION OF ANTIOXIDANT ENZYMES TARGETED TO MITOCHONDRIA}

As stated above, estrogens very actively upregulate the expression of superoxide dismutase and glutathione peroxidase. This is the basis of the powerful antioxidant effects of estrogens when administered to animals (or humans) in vivo.

We dissected the signaling pathway of the antioxidant effect of estrogen. First of all, estrogens have to bind to estrogen receptor. The use of albumin bound to estrogens indicated that the effects are mediated by membrane receptors rather than by intercellular ones. When cells were incubated with estrogen bound to albumin, the effect was similar to free estrogen. Estrogen does bind (most likely to estrogen receptor $\beta$, see below) and activates a signaling pathway leading to phosphorylation of MEKK which leads to activation of MEK and subsequent phosphorylation of ERK.

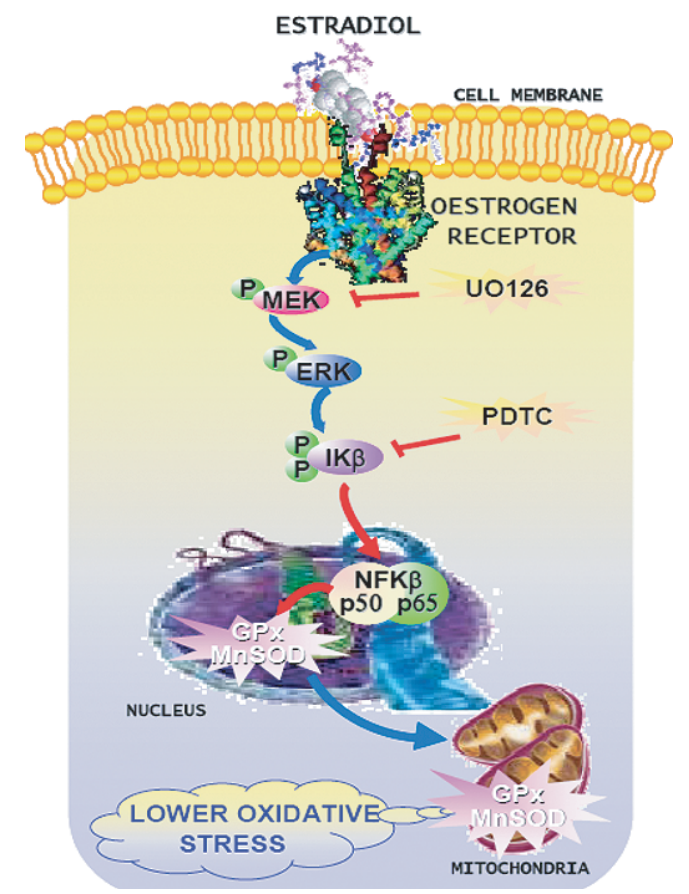

Fig. 1. Mechanism of antioxidant action of estradiol and genistein. The mechanisms of the upregulation of antioxidant enzymes by estradiol (a) or genistein (b) are very similar, involving binding to membrane estrogen receptors, activation of the MAP kinase pathway and upregulation of $\mathrm{NF} \kappa \mathrm{B}$ (reprinted from [36] (panel a), and from [17] (panel b).

Phospho-ERK phosphorylates IK $\beta$ and therefore activates $\mathrm{NF} \kappa \mathrm{B}$ which is translocated to the nucleus upregulating the expression of manganese superoxide dismutase and glutathione peroxidase. These enzymes are directed to mitochondria where they exert their antioxidant effects. The higher activity of these antioxidant enzymes results in a significantly lower release of peroxides from mitochondria and therefore is a potent protection against oxidative stress (see Fig. 1a) [15].

The favorable effects of estradiol on the redox balance in cells are seriously limited by their feminizing effects. Of course, estradiol cannot be administered to males and, particularly in the case of women, estrogen replacement therapy with estradiol has serious limitations because of the higher incidence of breast and uterine cancer as well as an increase in cardiovascular diseases [16]. Therefore, an alternative to estradiol had to be found. Because of the similar structure of estradiol and genistein, we determined that this phytoestrogen could be a valid alternative to estradiol. We tested its favorable effects on the upregulation of antioxidant enzymes, particularly superoxide dismutase in animals [17], and then we studied the pathway in 


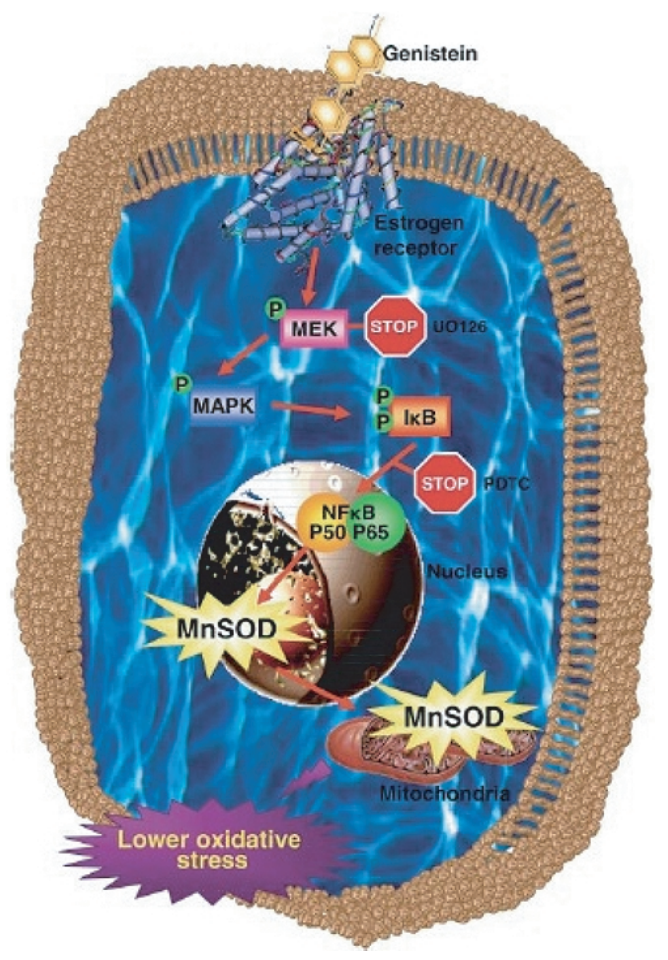

Fig. 1. continued.

MC7 cells in vivo. Figure 1b shows that genistein acts in a very similar way to that of estradiol, the pathway being: estrogen receptor $\rightarrow$ activation of $\mathrm{MEK} \rightarrow$ phosphorylation ERK $\rightarrow$ phosphorylation of IK $\beta \rightarrow$ translocation of $\mathrm{NF} \kappa \mathrm{B}$ to the nucleus. Figure $1 \mathrm{~b}$ shows how similar the pathway of genistein action is to that of estradiol [18]. In our opinion, a critical point is that the majority of the effect of genistein is mediated by estrogen receptor $\beta$ with only a very minor activation of estrogen receptor $\alpha$. Because the feminizing effects of estrogens are mediated by $\alpha$ activation, genistein is indeed a very useful alternative to estradiol to promote antioxidant effects in both health and disease, in particular in AD.

\section{MITOCHONDRIA FROM YOUNG FEMALES GENERATE LESS REACTIVE OXYGEN SPECIES IN THE PRESENCE OF AMYLOID- $\beta$ PEPTIDE THAN OLD ONES}

A $\beta$ was initially thought to cause neuronal toxicity because of extracellular plaque formation. However, approximately a decade ago, evidence began to increase regarding the intracellular toxicity of $\mathrm{A} \beta_{1-42}$ peptide [18]. The findings by the groups of Mark A.
Smith and George Perry, and also from that of Catarina Oliveira, were of particular importance, showing that mitochondria could produce higher amounts of peroxides when they were incubated with $\mathrm{A} \beta$ (see above).

The previous background on the gender differences in mitochondrial free radical production together with the different incidence in $\mathrm{AD}$ (being higher in females) led us to study the effect of $\mathrm{A} \beta$ on radical production by mitochondria from male and female Wistar rats. We found it surprising that ROS production from mitochondria from females was lower than that of males in the presence of $\mathrm{A} \beta$ peptide. This puzzling observation (in view of the higher incidence of AD in females) was solved when we obtained mitochondria from old female rats and measured peroxide production. We found that in old animals, mitochondria from females produced as many, or even more, peroxides than those from males. Therefore, we concluded that young females are protected against the toxicity of $\mathrm{A} \beta$ [11]. It is well known that estrogen levels do not fall in old rats (in contrast to what happens in women after menopause). However, the sensitivity of tissues to estrogens declines sharply with age [20]. Our studies show that mitochondria from old females are not protected against the toxicity of $\mathrm{A} \beta$ peptide, whereas those from young ones are.

\section{ROLE OF p38 IN THE CELLULAR PATHO-PHYSIOLOGY OF AD}

p38 is a MAP kinase which is of critical importance in the response cells to stress. In fact, p38 has been considered as a sensor of ROS in cells [21]. The importance of $\mathrm{p} 38$ in the possible phosphorylation of tau was first described as far back as 1997. This finding led the authors to conclude that cellular stresses might contribute to tau phosphorylation [22]. In fact, the same group of authors [23] considered that some of the isoforms of p38 were important candidates as tau kinases, and that they might be involved in the hyperphosphorylation of tau in AD. Zhu and Smith showed that p38 activation was induced by $\mathrm{A} \beta$ in a concentration dependent manner [24]. And in fact, $\mathrm{A} \beta$ toxicity was significantly decreased by inhibition of $\mathrm{p} 38$. Moreover, Cuenda and Russeau [25] suggested that indeed it was conceivable that members of the MAP kinase might play an important role in the phosphorylation of tau. Work in our laboratory showed that p38 is activated when neurons are incubated with $\mathrm{A} \beta$ [26]. So there is a mounting body of evidence that p38 is indeed a very important mediator in the hyperphosphorylation 

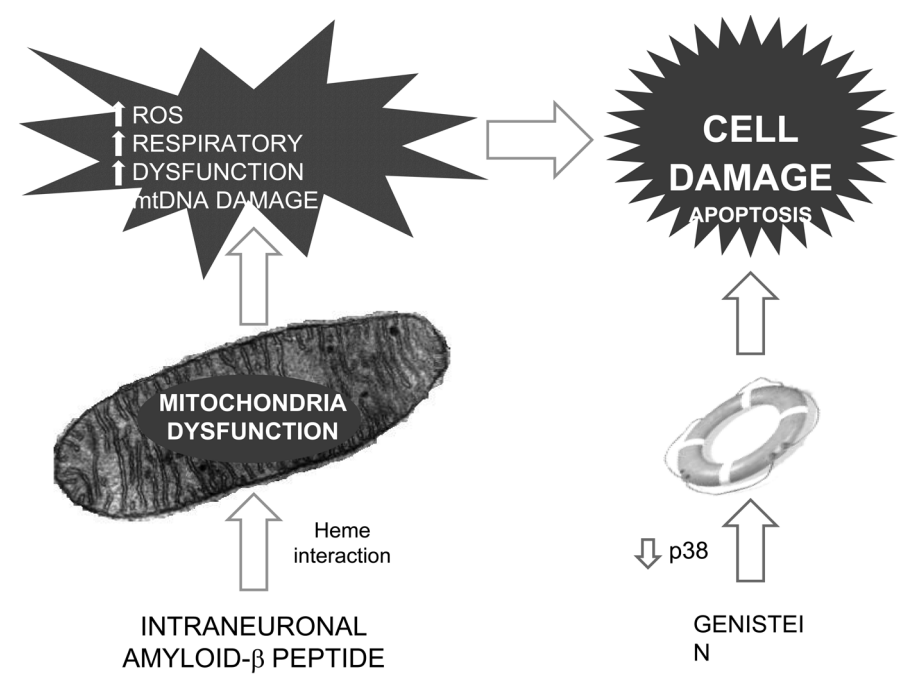

Fig. 2. Reactive oxygen species are involved in the mitochondrial toxicity of Alzheimer's disease. Amyloid- $\beta$ peptide causes an upregulation of p38 and genistein prevents it.

of tau. Recent work from our laboratory also showed that estradiol or genistein might be protective because they rescue neurons from phosphorylation of $\mathrm{p} 38$ and therefore inhibit $\mathrm{A} \beta$-induced cell death.

\section{ESTROGENIC COMPOUNDS PROTECT AGAINST MITOCHONDRIAL TOXICITY OF AMYLOID- $\beta$}

The fact that women have a higher incidence of AD than men, which happens after menopause, together with the idea that estrogens protect against ageassociated damage (some of it coming from our own laboratory $[14,15])$, has led many researchers to look for protective effects of estrogen and estrogenic compounds against the toxicity of $\mathrm{A} \beta$ and even as a treatment to AD. Work from Roberta Brinton's group has shown that estrogenic compounds act bind to estrogen receptors, activate cell signaling pathways, and finally result in restoration of normal glucose metabolism and mitochondrial function [27]. These authors propose that there are a number of protective mechanisms unleashed by estradiol which converge in mitochondrial protection. We, among others, underpinned the importance of mitochondrial toxicity in AD [11]. Therefore, estrogens are postulated as mitochondrial protectors against the damaging effects of $\mathrm{AD}$ via activation of both estrogen receptor $\alpha$ and $\beta$ [28].

Further evidence of the protective role of estradiol and estrogenic compounds, such as genistein, in the pathophysiology of $\mathrm{AD}$ also come from our laborato- ry in which we observed that either estradiol or genistein were able to prevent the increase of interleukin $1 \beta$ and TNF $\alpha$ caused by incubation of astrocytes with $\mathrm{A} \beta$ peptide [29]. Furthermore, we showed that estradiol or genistein were able to prevent COX2 expression induced by $\mathrm{A} \beta$. An important target of inflammation is iNOS, and this is very much upregulated (more than tenfold) in astrocytes when incubated with $5 \mu \mathrm{M} \mathrm{A} \beta$. When these astrocytes were incubated with $\mathrm{A} \beta$ and either genistein or estradiol, the upregulation of the expression of iNOS by A $\beta$ was completely prevented. So it appears that estrogens not only protect against neuronal toxicity of $\mathrm{A} \beta$ peptide but also against inflammation which is mainly caused by astrocytes in the disease. Some of the anti-inflammatory effects of estrogenic compounds may be mediated by the upregulation of PPARs [29]. So it appears that estrogens interfere with the pathophysiology of $\mathrm{A} \beta$ in a favorable way and they are likely to be protective against AD development. The possible clinical application of estrogens or estrogenic compounds in the prevention and treatment of $\mathrm{AD}$ is reported in the next paragraph.

\section{ESTROGENIC COMPOUNDS IN THE PREVENTION AND TREATMENT OF AD}

The protective effect of estrogenic compounds, which has been observed in a number of laboratories including our own, suggests a possibility for treatment or prevention of AD by these compounds. The Women's Health Initiative Memory Study (WHIMS) is a sub- 
study of the Women's Health Initiative (WHI) in which 7479 women enrolled were randomized to treatment with either estrogen if they were hysterectomized, or a combination of estrogen and a progestational agent if they retain the uterus. The principal end point was all cause dementia. The estrogen therapy was stopped in 2002 because of an increase in heart attack and breast cancer and the progestational agent was stopped in 2004 because of excessive strokes and the absence of cardiovascular benefit. Moreover, the treatments separately and combined revealed an increase in the cumulative hazard for probable dementia [30,31].

Estrogen replacement therapy has given conflicting results but with all factors considered, the problems associated with treatment with estradiol, particularly the increased incidence of cancer and cardiovascular disease, led researchers to favor phytoestrogens to protect against cognitive decline associated with AD.

Some hope was deposited in the possibility that estrogenic compounds in Ginkgo biloba might prevent $\mathrm{AD}$, but very recent evidence [32-34] indicates that Ginkgo biloba, normally taken by patients in the form of a controlled extract, does not prevent the loss of cognition in AD. Work from our laboratory [35] indicated that Ginkgo biloba is very protective against ageassociated mitochondrial damage. The failure of clinical trials with Ginkgo biloba together with problems associated with estrogen therapy indicate that the conditions have not been found to treat $\mathrm{AD}$ with estrogenic compounds, although hopes of finding the right situation to treat or prevent AD by interacting with estrogen receptors should not be given up and more experiments and clinical trials are indeed warranted.

\section{DISCLOSURE STATEMENT}

Authors' disclosures available online (http://www.jalz.com/disclosures/view.php?id=386).

\section{REFERENCES}

[1] Gill TM, Baker DI, Gottschalk M, Peduzzi PN, Allore H, Byers A (2002) A program to prevent functional decline in physically frail, elderly persons who live at home. $N$ Engl $J$ Med 347, 1068-1074.

[2] Alzheimer's Association, 2010 Alzheimer's Disease Facts and Figures, http://www.alz.org/documents_custom/report alzfactsfigures2010.pdf.

[3] Smith MA, Perry G, Richey PL, Sayre LM, Anderson VE, Beal MF, Kowall N (1996) Oxidative damage in Alzheimer's. Nature 382, 120-121.
[4] Pereira C, Santos MS and Oliveira C (1998) Mitochondrial function impairment induced by amyloid $\beta$ peptide on PC12 cells. Neuroreport 9, 1749-1755.

[5] Cardoso SM, Santos S, Swedlow RH, Oliveira CR (2001) Functional mitochondria are required for amyloid-mediated neurotoxicity. FASEB J 15, 1439-1441.

[6] Lustbader JW, Cirilli M, Lin C, Xu HW, Takuma K, Wang N, Caspersen C, Chen X, Pollak S, Chaney M, Trinchese F, Liu S, Gunn-Moore F, Lue LF, Walker DG,Kuppusamy P, Zewier ZL, Arancio O, Stern D, Yan SS, Wu H (2004) ABAD directly links $\mathrm{A} \beta$ to mitochondrial toxicity in Alzheimer's disease. Science 304, 448-452.

[7] Pereira C, Santos SM and Oliveira C (1999) Involvement of oxidative stress on the impairment of energy metabolism induced by $\mathrm{A} \beta$ peptides on PC12 cells: protection by antioxidants. Neurobiol Dis 6, 209-219.

[8] Casley CS, Canevari L, Land JM, Clark JB, Sharpe MA (2002) $\mathrm{B}$-amyloid inhibits integrated mitochondrial respiration and key enzyme activities. J Neurochem 80, 91-100.

[9] Boveris A, Oshino N, Chance B (1972) The cellular production of hydrogen peroxide. Biochem J 128, 617-630.

[10] Chance B, Sies H, Boveris A (1979) Hydroperoxide metabolism in mammalian organs. Physiol Rev 59, 527-605.

[11] Lloret A, Badía MC, Mora NJ, Ortega A, Pallardó FV, Alonso MD, Atamna H, Viña J (2008) Gender and age-dependent differences in the mitochondrial apoptogenic pathway in Alzheimer's disease. Free Radic Biol Med 44, 2019-2025.

[12] Atamna H, Boyle K (2006) Amyloid- $\beta$ peptide binds with heme to form a peroxidase: relationship to the cytopathologies of Alzheimer's disease. Proc Natl Acad Sci U S A 103, 33813386.

[13] Miquel J, Fleming JE (1984) A two-step hypothesis on the mechanisms of in vitro cell aging: cell differentiation followed by intrinsic mitochondrial mutagenesis. Exp Gerontol 19, 3136.

[14] Borrás C, Sastre J, García-Sala D, Lloret A, Pallardó FV, Viña J (2003) Mitochondria from females exhibit higher antioxidant gene expression and lower oxidative damage than males. Free Radic Biol Med 34, 546-552.

[15] Borrás C, Gambini J, Gómez-Cabrera MC, Sastre J, Pallardó FV, Mann GE, Viña J (2005) 17 $\beta$-oestradiol up-regulates longevity-related, antioxidant enzyme expression via the ERK1 and ERK2[MAPK]/NFkappaB cascade. Aging Cell 4, 113-118.

[16] Steinberg KK, Thacker SB, Smith SJ, Stroup DF, Zack MM, Flanders WD, Berkelman RL (1991) A meta-analysis of the effect of estrogen replacement therapy on the risk of breast cancer. JAMA 265, 1985-1990.

[17] Borrás C, Gambini J, Gómez-Cabrera MC, Sastre J, Pallardó FV, Mann GE, Viña J (2006) Genistein, a soy isoflavone, up-regulates expression of antioxidant genes: involvement of estrogen receptors, ERK1/2, and NFkappaB. FASEB $J \mathbf{2 0}$, 2136-2138.

[18] Mahn K, Borras C, Knock GA, Taylor P, Khan IY, Sugden D, Poston L, Ward JP, Sharpe RM, Vina J, Aaronson PI, Mann GE (2005) Dietary soy isoflavone induced increases in antioxidant and eNOS gene expression lead to improved endothelial function and reduced blood pressure in vivo. FASEB $J \mathbf{1 9}$, $1755-1757$

[19] Gouras GK (2002) Intraneuronal Alzheimer A $\beta 42$ accumulates in multivesicular bodies and is associated with synaptic pathology. Am J Pathol 161, 1869-1879.

[20] Bellino FL (2000) Nonprimate animal models of menopause: workshop report. Menopause 7, 14-24. 
[21] Dolado I, Swat A, Ajenjo N, De Vita G, Cuadrado A, Nebreda AR (2007) p38 $\alpha$ MAP kinase as a sensor of reactive oxygen species in tumorigenesis. Cancer Cell 11, 191-205.

[22] Reynolds CH, Nebreda AR, Gibb GM, Utton MA, Anderton BH (1997) Reactivating kinase/p38 phosphorylates tau protein in vitro. J Neurochem 69, 191-198.

[23] Reynolds CH, Betts JC, Blackstock WP, Nebreda AR, Anderton BH (2000) Phosphorylation sites on tau identified by nanoelectrospray mass spectrometry: differences in vitro between the mitogen-activated protein kinases ERK2, c-Jun Nterminal kinase and P38, and glycogen synthase kinase- $3 \beta . J$ Neurochem 74, 1587.

[24] Zhu X, Mei M, Lee HG, Wang Y, Han J, Perry G, Smith MA (2005) P38 activation mediates amyloid- $\beta$ cytotoxicity. Neurochem Res 30, 791-796.

[25] Cuenda A, Rousseau S (2007) p38 MAP-kinases pathway regulation, function and role in human diseases. Biochim Biophys Acta 1773, 1358-1375.

[26] Vallés SL, Borrás C, Gambini J, Furriol J, Ortega A, Sastre J, Pallardó FV, Viña J (2008) Oestradiol or genistein rescues neurons from amyloid $\beta$-induced cell death by inhibiting activation of p38. Aging Cell 7, 112-118.

[27] Brinton RD (2008) Estrogen regulation of glucose metabolism and mitochondrial function: therapeutic implications for prevention of Alzheimer's disease. Adv Drug Deliv Rev 60, 15041511.

[28] Wang JM, Irwin RW, Brinton RD (2006) Activation of estrogen receptor $\alpha$ increases and estrogen receptor $\beta$ decreases apolipoprotein E expression in hippocampus in vitro and in vivo. Proc Natl Acad Sci U S A 103, 16983-16988.

[29] Valles SL, Dolz-Gaiton P, Gambini J, Borras C, Lloret A, Pallardo FV, Viña J (2010) Estradiol or genistein prevent Alzheimer's disease-associated inflammation correlating with an increase PPAR gamma expression in cultured astrocytes. Brain Res 1312, 138-144.

[30] Shumaker S, Legault C, Kuller L, Rapp SR, Thal L, Lane
DS, Fillit H, Stefanick ML, Hendrix SL, Lewis CE, Masaki K, Coker LH, Women's Health Initiative Memory Study (2004) Conjugated equine estrogens and incidence of probable dementia and mild cognitive impairment in postmenopausal women. Women's Health Initiative Memory Study. JAMA 291, 2947-2958.

[31] Shumaker S, Legault C, Rapp S, Thal L, Wallace R, Ockene J, Hendrix S, Jones B III, Assaf A, Jackson R, Kotchen J, Wassertheil-Smoller S, Wactawski-Wende J (2003) Estrogen plus progestin and the incidence of dementia and mild cognitive impairment in postmenopausal women. The women's health initiatitive memory study: a randomized controlled trial. JAMA 289, 2651-2662.

[32] Snitz BE, O'Meara ES, Carlson MC, Arnold AM, Ives DG, Rapp SR, Saxton J, Lopez OL, Dunn LO, Sink KM, DeKosky ST; Ginkgo Evaluation of Memory (GEM) Study Investigators (2009) Ginkgo biloba for preventing cognitive decline in older adults: a randomized trial. JAMA 302, 2663-2670.

[33] Yancheva S, Ihl R, Nikolova G, Panayotov P, Schlaefke S, Hoerr R; GINDON Study Group (2009) Ginkgo biloba extract EGb 761(R), donepezil or both combined in the treatment of Alzheimer's disease with neuropsychiatric features: a randomised, double-blind, exploratory trial. Aging Ment Health 13, 183-190.

[34] Schneider LS (2008) Ginkgo biloba extract and preventing Alzheimer disease. JAMA 300, 2306-2308.

[35] Sastre J, Millán A, García de la Asunción J, Plá R, Juan G, Pallardó, O'Connor E, Martin JA, Droy-Lefaix MT, Viña J (1998) A Ginkgo biloba extract (EGb 761) prevents mitochondrial aging by protecting against oxidative stress. Free Radic Biol Med 24, 298-304.

[36] Vina J, Borras C, Gambini J, Sastre J, Pallardo FV (2005) Why females live longer than males? Importance of the upregulation of longevity-associated genes by oestrogenic compounds. FEBS Lett 579, 2541-2545. 